\title{
Conceptual Framework for Measurement and Application of Public Sector Opportunity Cost of Capital
}

\author{
Kaia Kask
}

\begin{abstract}
In this paper, a conceptual framework for the measurement and application of opportunity cost of capital for the public sector budgetary purposes is elaborated. The paper fills the gap to offer a structured overview of discount rate classifications discussed in literature, also how these discount rates are measured and finally applied to various long-term investment opportunities faced by the public sector. The final result should give the answer to the question, whether there should be used different discount rates to different public sector investment projects or maybe there is the one and the only universal discount rate applicable to all cases?
\end{abstract}

Index Terms-Public sector investment, opportunity cost of capital, social opportunity cost, social rate of time preference.

\section{INTRODUCTION}

The topicality of the application of appropriate opportunity cost of capital in public sector has been proven by the number of researchers done on the field during the last century. Nevertheless, there is still an ongoing debate among scholars, what would be the most optimal long-term discount rate to use in case of public sector intra- and inter-generational investments. The main problem arises from the well-recognized fact that the government should allocate its budget to maximize social welfare [1]. When the net present value (NPV) is used as the basis of project or investment choice, the discount rate critically influences budget allocation; but yet there is no consensus on the optimal discount rate that would maximize social welfare [1].

Therefore, in terms of long period of timeframe, the right choice over the appropriate cost of capital on public sector level has a remarkable importance not only from theoretical viewpoint, but has also important practical implications by guaranteeing most efficient allocation of public sector resources in the long-run [2], for the next generations.

The aim of the current paper is to elaborate a conceptual framework for the classification, measurement and application of appropriate discount rate for public sector investments. In order to fulfill the aim, there is used an explorative qualitative methodology. At first, a thorough investigation of academic literature was done. Thereafter the findings were systemized and final result was presented in a Fig. 1, which is found in Appendix 1.

Manuscript received August 19, 2013; revised October 20, 2013.

Kaia Kask is with the Faculty of Economics and Business Administration, the Institute of Finance, University of Tartu, Estonia (e-mail: kaia.kask@ut.ee).

\section{LITERATURE REVIEW}

So far, the literature on public sector discounting has brought many important insights to the topic, but still there remain wide differences on some of the fundamental issues [3]. The main argue in literature goes around socially sensitive domains, such as [4]:

1) the adequate assessment of discount rate, being appropriate for the governmental projects and investments, and

2) the question about proper discounting method, depending on the discounting function.

The debate about the ethics on positive discounting of public sector cash flows states back to already 1920s, beginning with the seminal works on the topic of [5] and [6], who brought up the questions about the intra- and inter-generational views on discounting. According to normative perspective of social approach, based on [6], a popular argument is that ,the ethical presumption that all individuals, including those living in different generations, should be valued the same"[7], i.e. the future generations ought to be given exactly the same weight as the current alive ones and therefore there should be no discounting of future relative to present utility. [8] Since then, a lot of discussions have been developed by several numbers of scholars about the application of appropriate discount rate used in public sector budgetary purposes.

\section{Methodology}

Regarding to the discounting method, there are two basic views in literature, which also correspond to the discount rate problem [4]:

1) exponentially discounted cash flow (CF) function, where it is assumed that the preferences are time-consistent;

2) hyperbolic and quasi-hyperbolic discount function, where the preferences are assumed to be time-inconsistent (i.e. present-based or hyperbolic preference).

The neoclassical way of thinking goes according to the exponential discounting path, where it is assumed that the agents have a stationary time preference and they discount the future at a constant exponential rate [9]. Therefore, when using the exponential discounting, there is an undervaluation of distant future events due to the geometrical reduction of the function $(1+i)^{-t}[10]$ and the near to the present events are valued more.

However, there are some strong empirical evidences that people by nature are discounting hyperbolically, i.e. applying larger annual discount rates to near-term returns than to 
returns to the distant future [10], which is well observed in researches, based on animal and human behavior. For example, [11]-[13] concluded that the discount functions are generalized hyperbolas, i.e. events $\tau$ periods away are discounted with factor $(1+\alpha \tau)^{-\gamma / \alpha}$, with $\alpha, \gamma>0$. Such discount functions imply a monotonically falling discount rate, where the discount structure sets up a conflict between today's preferences and the preferences which will be held in the future, implying that preferences are dynamically inconsistent. ${ }^{1}$ [14] Therefore, according to hyperbolic discounting, the discount rate declines as the time-horizon increases.

Quasi-hyperbolic function in discounting was first proposed by [15] for intergenerational analysis and then applied by [14] for intrapersonal analysis. [9] What concerns the discount rate corresponding to the way of discounting, then [9], [16] and [17] were the first scholars to understand that discount rates in the short run are higher than in the long run.

According to [3], there is possible to observe several various viewpoints about the appropriate discount rate applied to the long-term cash-flows from public sector investments, e.g.:

1) some would discount at a rate appropriate for a similar private investment;

2) others would advocate a rate reflecting the opportunity cost of displaced private sector investment;

3) some would say that the rate should instead reflect, wholly or in part, a „social time preference“ rate, perhaps derived from a risk-free market rate, or perhaps from other sources; they might also say that, as well as discounting, the impact of the public spending on private sector activity should be reflected by applying shadow prices;

4) some would say that, although public sector rates differ from those appropriate to the private sector, they too should vary with the type of investment.

Similar kind of views and arguments has been applied also in several intra- and intergenerational discussions (see for example [18]).

\section{CONCEPTUAL FrAMEWORK}

For the current research, a theoretical conceptual framework (see Fig. 1 in Appendix 1) for classifying, measurement and application of discount rates for the public sector budgetary purposes was elaborated, in order to clarify the research question, whether there should be used different discount rates to different public sector investment projects or maybe there is the one and the only universal discount rate applicable to all cases.

As it is seen from Fig. 1 in Appendix 1, then the starting point is from the classification of discount rates. According to the literature, there are two different approaches - i.e., privately optimal financial approach and socially optimal

\footnotetext{
${ }^{1}$ For example, from today's perspective, the discount rate between two far off periods, $\mathrm{t}$ and $t+1$, is a long-term low discount rate. However, from the time $t$ perspective, the discount rate between $t$ and $t+1$ is a short-term high discount rate. [13]
}

social approach for the measurement of discount rate. The social approach to discount rate estimation is discussed the most in academic literature, and it is possible to identify two different viewpoints or perspectives to how the discount rates are measured. These are normative or prescriptive viewpoint (which is basically based on the opinion of the assessor of the discount rate) and positive or descriptive viewpoint, where the efficiency criterion is taken into account.

The next step was to identify, according to theory, and model the classification of the discount rate measurement methods. The result of the analysis of the literature shows that there are two possible ways of measuring the discount rate under the financial approach - i.e., risk-adjusted discount rates and option-based models for calculating the appropriate discount rate. On the other hand, as it is widely seen from different kind of researches, the measurement methods under social approach are prevailing. Here, the well-described social rate of time preference (SRTP) method is classified as a normative approach to the assessment of discount rate and social opportunity cost (SOC) is viewed under the positive perspective.

The following step was to identify the discount rate measurement methods according to common practice. In this section the most difficult part was to find out the appropriate practical method for depicting the financial approach. It seems to the author that the appropriate method could be either the borrowing cost of public sector or the rate of the government.

Further, the application of previously identified types of discount rates by the public sector in practice was analyzed. In general, it seems to be clear, that in terms of cost-efficiency analysis and also cost-benefit analysis (CBA), the appropriate measurement method of discount rate to apply would be socially optimal approach. But in terms of, for example, cost-effectiveness analysis, lease-purchase analysis or governmental asset-sale analysis, the most appropriate way to choose the right discount rate, is to use the financial approach to value the appropriate opportunity cost of capital.

\section{CONCLUSION}

Despite of the almost a century-long discussion about the opportunity cost of capital for public sector, the actuality of the topic still holds. The current paper presents a structured conceptual framework over the research done so far, in order to clarify the classification issues of the discount rate, the possibilities of measurement methods and techniques in theory and in practice for the public sector and to which projects of those discount rate methods are appropriate to apply in practice.

The result of the qualitative research show that there are mainly two approaches to the measurement of opportunity cost of capital for the public sector and the application of them depends on the nature of the cash flows of the investment project and the analysis method used. Therefore, the final conclusion of the research would be the proposition that there is no universally existing discount rate that would be appropriate for all projects and for all occasions in terms of public sector. Instead, the decision-makers have to bear in 
mind that for different kind of projects should be applied different kind of discount rate. The actual methodology, how to measure the right discount rate, depends on the context and the researcher, but the current framework gives some guidelines and directions to make the valuation process of the appropriate discount rate easier for the decision-makers.

\section{APPENDIX}

Appendix 1. Conceptual framework for the assessment of appropriate discount rate for public sector budgetary purposes.

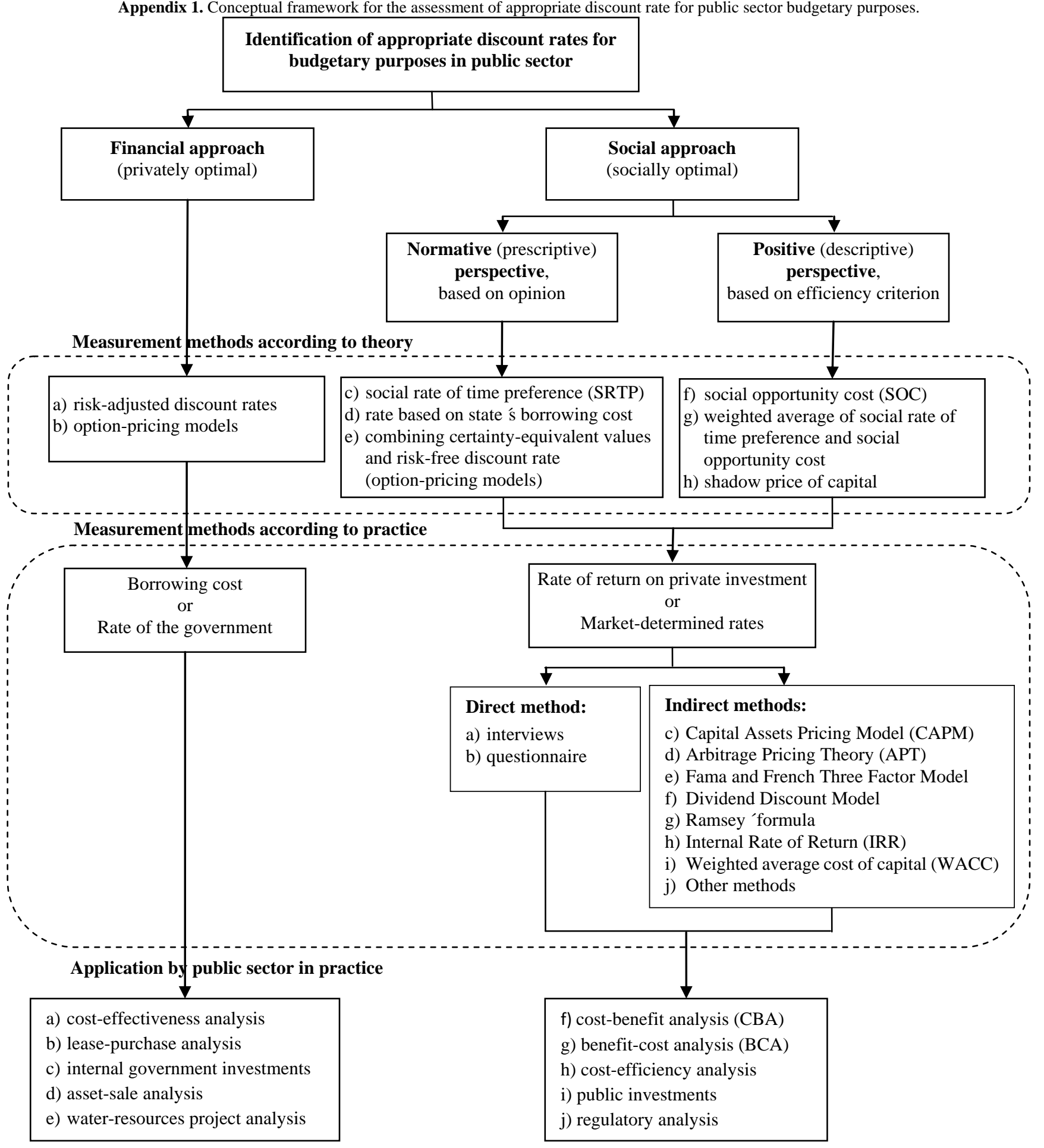

Fig. 1. The classification, measurement and application of discount rates in public sector according to theory and practice. (Source: compiled by the author, based on the literature).

\section{REFERENCES}

[1] S. Park, "Optimal Discount Rates for Government Projects," International Scholarly Research Network, ISRN Economics, vol. 2012, Article ID 982093, pp. 13.

[2] P. Sander, O. Lukason, and K. Kask, "Discount rate for government projects: the case of government real estate in Estonia," Theory and
Practice of Economic Policy, 2011, pp. 212-227, Berliin, Tallinn: Berliner Wissenchafts-Verlag, Mattimar.

[3] M. Spackman, "Time discounting and of the cost of capital in government," Fiscal Studies, vol. 25, no. 4, pp. 467-518, 2004.

[4] S. R. Grenadier and N. Wang, "Investment under uncertainty and time-inconsistent preferences," Journal of Financial Economics, vol. 84, no. 1, pp. 2-39, 2007.

[5] A. C. Pigou, The Economics of Welfare, Macmillan, London, 1920. 
[6] F. P. Ramsey, "A Mathematical Theory of Saving," Economic Journal, vol. 38, no. 152, pp. 543-59, Dec. 1928.

[7] H. Kohyama. (2006). Selecting Discount Rates for Budgetary Purposes. Harvard Law School. [Online]. Briefing Paper no. 29. pp. 37. Available: http://law.harvard.edu/faculty/hjackson/DiscountRates_29.pdf

[8] G. Marini and P. Scaramozzino, "Social time preference," Journal of Population Economics, vol. 13, pp. 639-645, Springer-Verlag, 2000.

[9] M. Cropper, D. Laibson, "The Implications of Hyperbolic Discounting for Project Evaluation," Policy research working paper 1943, The World Bank, pp. 13, July 1998.

[10] S. C. Rambaud and M. J. M. Torrecillas, "Social discount rate: a revision," Anales De Estudios Económicos y Empresariales (Universidad de Valladolid), 2006, vol. 16, pp. 75-98.

[11] G. W. Ainslie, Picoeconomics: The Strategic Interaction of Successive Motivational States within the Person, Cambridge: Cambridge University Press, 1992.

[12] G. Loewenstein and D. Prelec, "Anomalies in Intertemporal Choice: Evidence and an Interpretation," Quaterly Journal of Economics, vol. 57, no. 2, pp. 573-598, 1992.

[13] D. I. Laibson. (June 1996). Hyperbolic discount functions, undersavings, and savings policy. NBER Working Paper Series, Working Paper 5635, National Bureau of Economic Research. [Online]. $\quad$ pp. $51 . \quad$ Available: http://www.nber.org/papers/w5635.pdf?new_window=1].

[14] D. I. Laibson, "Golden eggs and hyperbolic discounting," The Quarterly Journal of Economics, vol. 112, pp. 443-477, May 1997.

[15] E. S. Phelps and R. A. Pollak, "On Second-Best National Saving and Game-Equilibrium Growth," Review of Economic Studies, vol. 35, pp. 185-199, 1968.
[16] R. H. Strotz, "Myopia and Inconsistency in Dynamic Utility Maximization," Review of Economic Studies, vol. 23, pp. 165-180, 1956.

[17] R. J. Herrnstein, "Aperiodicity as a factor in choice," Journal of the Experimental Analysis of Behavior, vol. 7, no. 2, pp. 179-182, 1964.

[18] K. J. Arrow, M. C. Cropper, C. Gollier, B. Groom, G. M. Heal, R. C. Newell, W. D. Nordhaus, R. S. Pindyck, W. A. Pizer, P. R. Portney, T. Sterner, R. S. J. Tol, and M. L. Weitzman. (December 2012). How Should Benefits and Costs Be Discounted in an Intergenerational Context? The Views of an Expert Panel. Resources for the Future Discussion Paper (RFF DP) 12-53. [Online]. pp. 34. Available: http://www.rff.org/RFF/Documents/RFF-DP-12-53.pdf

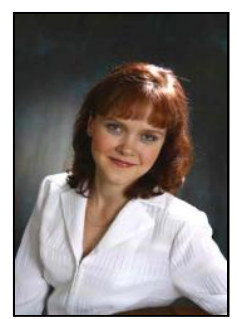

Kaia Kask was born in Tartu on August 5, 1972. She is working since 1994 as a lecturer of corporate and real estate finance at the University of Tartu, Estonia. In 2000, she attained the master's degree at Stockholm University and currently is studying as a doctoral student at the University of Tartu. Her major research fields are real estate finance and investment (majoring in topics of real estate valuation and public sector real estate management) and also corporate finance.

Ms. Kask is the member of the exam commission of real estate appraiser's certification in Estonia since 1999. In 2008, she was named as a honorary member of the NPO KinnisvaraMagnaadid (Real Estate Tycoons) - the fellowship of real estate students and professionals aiming to improve the quality of Estonian education in real estate sector. She has been also the ERASMUS program coordinator during 2002-2006 and the organizer of several international conferences at the University of Tartu. 